\title{
Features, Mechanism of the Barrier Layer in the Tropical Pacific Ocean and its Relationship with ENSO
}

\author{
Aijun Pan*, Changshuo Liang and Xiaofang Wan
}

Third Institute of Oceanography, Ministry of Natural Resources, China

\section{ISSN: 2578-031X}

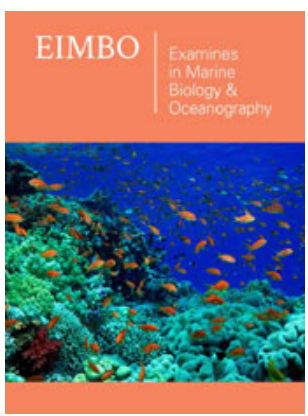

*Corresponding author: Aijun Pan, Ocean Dynamics Lab, Third Institute of Oceanography, Ministry of Natural Resources, China

Submission: 制September 30, 2019

Published: 海October 17, 2019

Volume 3 - Issue 2

How to cite this article: Aijun $\mathrm{P}$, Changshuo L, Xiaofang W.Features, Mechanism of the Barrier Layer in the Tropical Pacific Ocean and its Relationship with ENSO. Examines Mar Biol Oceanogr. 3(2). EIMB0.000556.2019.

DOI: 10.31031/EIMBO.2019.03.000556

Copyright@ Aijun Pan, This article is distributed under the terms of the Creative Commons Attribution 4.0 International License, which permits unrestricted use and redistribution provided that the original author and source are credited.

\begin{abstract}
The temperature and salt characteristics of the Barrier Layer (BL) play an important role in many ocean thermodynamic processes, especially for the strongest interannual signal in ocean-atmosphere coupled systems, the ENSO. BL studies has received attention from large-scale international cooperation marine survey projects such as Toga, Toga-Coare and Toga-Coare-Iop. Since the equatorial ocean plays an important role in regulating global climate changes, researchers first carried out relevant researches on the BL in the equatorial Pacific oceans, especially the western Pacific warm pool region. Here, the features, mechanism of the BL in the tropical Pacific Ocean, its evolution during different types of ENSO events and challenges we are facing, are summarized in detail.
\end{abstract}

Keywords: Barrier layer; Ocean atmosphere coupled system; Tropical Pacific ocean; Warm pool; ENSO

\section{Significance}

Ocean temperature, salinity and density have obvious vertical gradient distribution in the upper ocean, forming the corresponding thermocline, halocline and pycnocline. Above the thermocline and the pycnocline is referred to the isothermal layer and the isopycno layer, respectively. In most cases, these two layers are approximately equal. However, Lindstrom et al. [1] first observed that the thickness of the isothermal layer is significantly larger than that of the isopycno layer in two voyage observations in the western Pacific warm pool. That is, beneath the uniform density layer and above the thermocline, there exists a layer of water whose density increases sharply with depth and the temperature remains nearly uniform, which is named as Barrier Layer (BL) (Figure 1) Ando \& McPhaden [2].

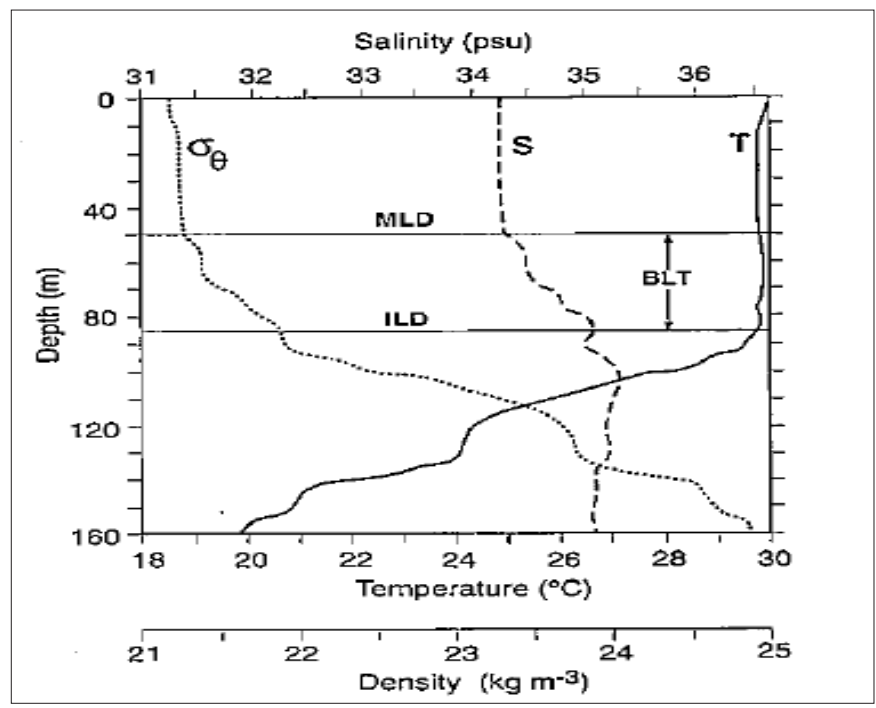

Figure 1: Vertical distribution of temperature (solid line), salinity (dotted line), density (dashed line) and thickness of mixed layer and barrier layer.

Station: $0.01^{\circ} \mathrm{S}, 153.93^{\circ} \mathrm{E}$; Time: April 29, 1994. Ando \& Mc Phaden [2].

Due to the presence of the BL, it will have a major impact on the thermal structure of the upper ocean. For example, the vertical distribution of temperature in the BL is uniform, effectively suppressing the vertical transport of sea surface heat flux to the interior of the ocean, 
so that the heat of the mixed layer and the thermocline cannot be effectively exchanged Godfrey \& Lindstrom [3]. Studies have shown that when the above-mentioned mixed layer is getting warmer, the occurrence frequency of the BL increases, and the thick BL weakens entrainment of the cold water from beneath of the thermocline to the mixed layer and correspondingly, the vertical turbulent mixing efficiency decreases Ando \& McPhaden [2]. Lewis et al. [4] showed that after the formation of the BL, the salinity stratification would inhibit downward penetration of the turbulent mixing into the ocean, consistent with Ando \& McPhaden [2] result. The BL favors formation of a thin mixed layer in the upper ocean and as a result, the wind turbulence and non-solar heat fluxes are confined within the upper mixing layer, and only the solar heat flux is not affected by the salinity stratification and can penetrate deep into the interior of the ocean. Similarly, the existence of the BL limits the external wind disturbance momentum to the thinner mixed layer, so that the convergence of the energy of the warm pool surface produces stronger zonal flow, meaning that the surface warm water can move more rapidly under the forcing of surface wind Vialard \& Delecluse [5]. In particular, when significant inversion temperature zone occurs due to the presence of the $\mathrm{BL}$, that is, the temperature of the barrier layer is greater than that of the mixed layer, the mixing processes such as entrainment and diffusion at the bottom of the mixed layer would transmit heat from the BL upward to the mixed layer, and may cause positive sea surface temperature anomalies Smyth et al. [6].

Jiang \& Chen [7] indicated that the distribution of BL is closely related to the El Niño-Southern Oscillation (ENSO) cycle, during El Niño, the whole BL moves eastward. OGCM studies demonstrated that the BL is currently occurring in the Western Pacific (WP) and Tropical Convergence Zone (ITCZ). In the western Pacific, the BL exhibits strong interannual variations associated with ENSO variability. The BL changes the thermal budget of the surface layer by turning on/off of the entrainment cooling at the base of the mixed layer. Besides, most of the momentum input by wind stress is confined within the surface of the fresh warm pool and produces strong eastward ocean currents in response to the Westerly Wind Bursts (WWBs). After the WWBs, the combined effects of zonal transport and mixing results in eastward shift of a thick barrier along the equator, which is proved to be conducive to the development of unstable air-sea coupling processes Vialard \& Delecluse [8]. Maes et al. [9] verified the important role of the BL in the warm-pool dynamic processes and El Nino evolution through a Pacific air-sea coupled model. It shows that if the barrier layer of the warm pool is removed, the El Nino event will be less or even vanishes.

\section{Features of the BL}

Sprintall \& Tomczak [10] used Levitus data to analyze for the first time the seasonal characteristics of the tropical Pacific BL and pointed out that the BL in the tropical western Pacific is thicker in spring and winter, especially in the warm pool, with a maximum of more than $50 \mathrm{~m}$. Comparatively, the BL is thinner in summer and autumn, with a maximum thickness of about $25 \mathrm{~m}$. Montegut [11] analyzed the seasonal variation of the global oceanic BL thickness field using 4,449,571 CTD, XBT and MBT data obtained during 1941-2002 and concluded that the thickest BL in the tropical western Pacific can reach up to 60m (Figure 2).

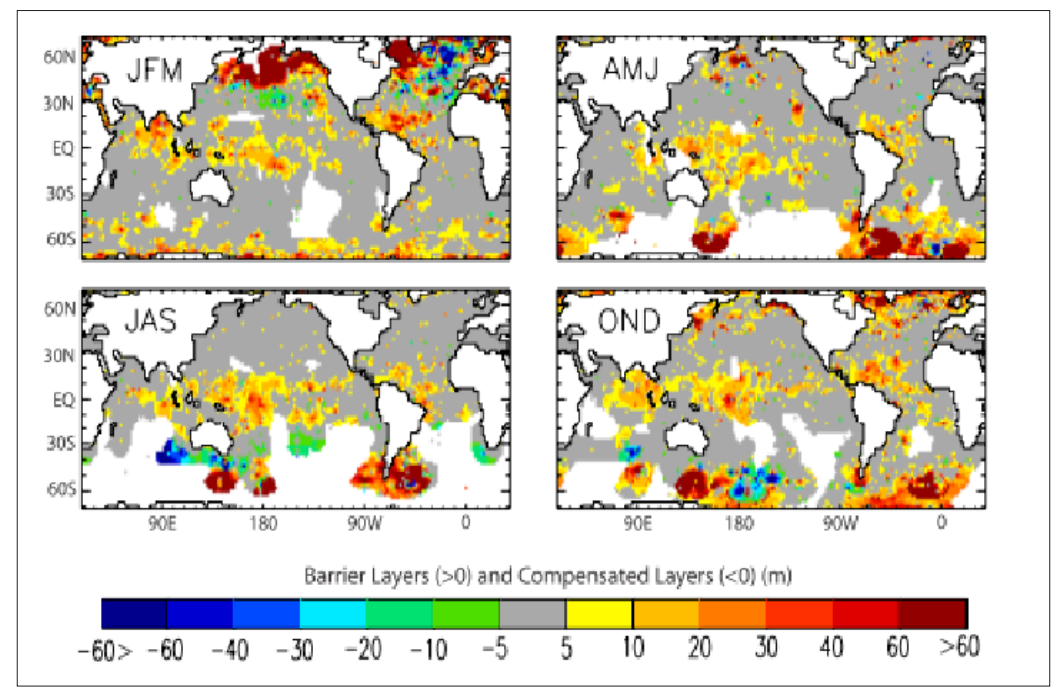

Figure 2: Seasonal distribution of barrier layer thickness Montegut [11].

Jiang \& Chen [7] used the Argo temperature data from 2000 to 2008 to analyze the climatic and low-frequency characteristics of the BL thickness in the tropical Pacific Ocean. It reveals that the thicker BL is mainly located in the western Pacific, specifically, the warm pool area, where it reaches more than $30 \mathrm{~m}$. Meanwhile, there are three distinct branches of the BL distributed in the latitude band of about $15^{\circ} \mathrm{N}, 5^{\circ} \mathrm{N}$ and $12^{\circ} \mathrm{S}$ from north to south, and the branch extending from the warm pool area to the east to $120^{\circ} \mathrm{W}$. The thickness of the BL of these three branches is about 10 to $20 \mathrm{~m}$, smaller than that of the warm pool zone. Among them, the climatic $\mathrm{BL}$ on the $12^{\circ} \mathrm{S}$ latitude belt is the thickest, the $15^{\circ} \mathrm{N}$ latitude belt is the second, and the $5^{\circ} \mathrm{N}$ latitude belt is the thinnest (Figure 3); [12]. 


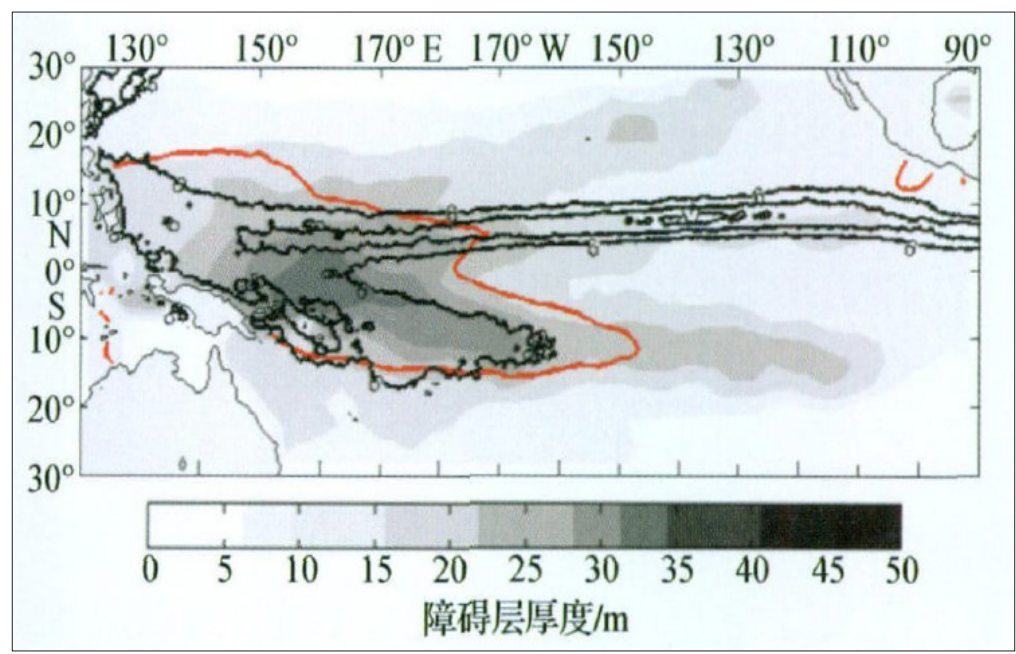

Figure 3: Thickness distribution of climatic barriers in the tropical Pacific Jiang $\&$ Chen [7]. (The shaded part represents the thickness of the barrier layer; the red line represents the $28.5{ }^{\circ} \mathrm{C}$ isotherm; the black line represents the precipitation contour; The unit is $\mathrm{mm} / \mathrm{d}$ and the precipitation contour interval are $3 \mathrm{~mm} / \mathrm{d}$ ).

\section{Formation Mechanism of the BL}

Previous studies have shown that thick BL tends to formed under the combined effects of low wind speed, high precipitation, weak net heat flux and vertical shear of zonal flow Chen [12] and Bosc et al. [13]. However, the dominant mechanism responsible for BL generation may differ from time to time and location to location. Sprintall \& Tomczak [10] argued that the thicker BL in the warm pool area are mainly caused by local precipitation. Vialard \& Delecluse [8] have shown that in the equatorial region and the $3^{\circ}-8$ ${ }^{\circ} \mathrm{S}$ latitude zone, the thicker BL is mainly induced by the subduction mechanism. Among them, the BL in the equatorial region is mainly triggered by the strong subsidence near the SSSF, while the SSSF is formed by convergence of the high saline water from the central Pacific and the freshwater from the western Pacific. The BL of the $3^{\circ}-8^{\circ} \mathrm{S}$ band is the result of thinned surface mixed layer from both submerged sinking of the southern equatorial current and freshening of the surface water. As to the freshening of the surface water, it is found to formed by the heavy rainfall and the eastward less saline equator jet. Comparatively, BL formation under ITCZ is simple and is mainly related to local precipitation processes.

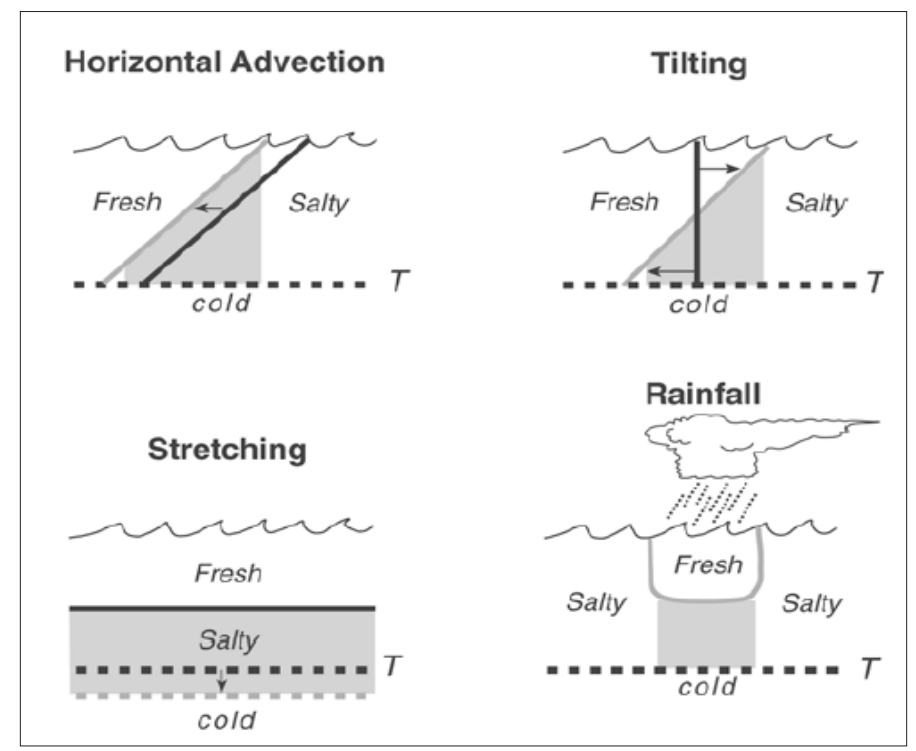

Figure 4: Scheme of BL formation mechanism Cronin \& McPhaden [14].

Cronin \& McPhaden [14] used the anchor data of the Tropical Atmospheric Ocean (TAO) from 1989 to 1994 to analyze the formation of thick BL under two Westerly Wind Burst (WWB). Case 1 found that in the condition of the westerly outbreak, the thickness of BL near $\left(0^{\circ}, 165^{\circ} \mathrm{E}\right)$ is about $100 \mathrm{~m}$ in November 1989 . During this period, the zonal and meridional advection of the surface fresh water from the west and the north is the main cause leading to the thick $\mathrm{BL}$, and the precipitation is the second contributor. Case 2 showed that given conditions of the westerly outbreak, the thickness of $\mathrm{BL}$ near $\left(0^{\circ}, 160^{\circ} \mathrm{E}\right)$ and $\left(0^{\circ}, 165^{\circ} \mathrm{E}\right)$ reached about 
$60 \mathrm{~m}$ in October 1992. For this case, it is revealed that the WWB induced latitudinal convergence increases the latitudinal salinity gradient, and then the surface-enhanced wind-driven flow tilts the latitudinal salinity gradient to the vertical orientation, creating a shallow halocline above the top of the thermocline and as a result, the BL is formed. Generally, four specific formation mechanisms (Horizontal Advection, Tilting, Stretching, Rainfall) for BL has been summarized and demonstrated as in Figure 4.

\section{Relationship with ENSO}

Using CTD data obtained from 1976 to 1994, Ando \& McPhaden [2] compared changes of the BL thickness in the equatorial Pacific ocean between the normal, El Niño and La Nina periods. The results show that in the normal state (non-ENSO years), the thicker BL is about $20-40 \mathrm{~m}$ and is mainly confined between 160E-160W. During El Niño period, the BL of the western equatorial Pacific is getting thinner and is only $20 \mathrm{~m}$. Whilst in La Niña years, the BL of the western equatorial Pacific is thickened to 20-30m. Maes et al. [15] verified the important roles of the BL in the warm-pool dynamic processes and the induction of the El Nino events through the Pacific Ocean-atmosphere coupling model simulations. It suggested that El Nino events will be less or even vanish if the warm pool BL is removed from the model. By establishing a coupling model for the equatorial Pacific ocean, Maes et al. [9] further testified the importance of the BL of the equatorial western Pacific warm pool in heat storage, pointing out that the stored heat is a necessary precondition for El Nino generation.

Liu et al. [16] analyzed the vertical profile data of WOD05 and revealed that the interannual variation of the BL thickness in the tropical Pacific is closely related to the ENSO cycle. The thickness of BL west of $160{ }^{\circ} \mathrm{E}$ is thicker in La Nina years than that of normal years and, conversely, it will be thinner during El Nino period. For the tropical Pacific Ocean east of $160^{\circ} \mathrm{E}$, in La Nina year, due to the decrease of precipitation, the BL becomes thinner, whilst during El Nino period, the BL will become thicker due to subduction of saline water on the eastern edge of the warm pool. Wang et al. [17] used oceanic assimilation data (SODA) data to study the interannual variations of the $\mathrm{BL}$ in association with El Niño/Southern Oscillation (ENSO). Two dominant mode of the BL are extracted with Empirical Orthogonal Function (EOF) method and, they are believed to be closely related to the diversity of ENSO events. EOF1 mainly reflects the comprehensive response to the eastern type El Niño event (EPEN), while EOF2 is linked with the central El Niño event (CPEN). During the EPEN, an unusually thick BL appears in the eastern part of the date line, which can be attributed to horizontal ocean advection, enhanced precipitation and sinking Kelvin waves. And along with the evolution of the EPEN, the thick BL moves latitudinally following the Sea Surface Salinity Front (SSSF) and propagates eastward to the Central Pacific Ocean. As for the CPEN, the anomalous thick BL is mainly confined to the regime between $160^{\circ} \mathrm{E}$ and $180^{\circ}$ around the SSSF and is formed by Ekman pumping, rainfall and the latitudinal ocean advection.

\section{Conclusion}

The tropical Pacific Ocean is the widest among the global tropical oceans. It has not only obvious seasonal changes, but also obvious interannual and interdecadal variations. These changes can not only affect other tropical areas through the oceanic and atmospheric bridges, but also cause changes of the global climate. Whilst ENSO is the strongest interannual signal of the Sea Surface Temperature (SST) in the tropical Pacific (Figure 4). Although the ENSO phenomenon is confined within the tropical Pacific region, numerical simulations and observational analysis has indicated that its occurrence will influence the environment and society in almost every part of the world McPhaden et al. [18].

Since the BL of the warm pool plays an important role in the formation and development of ENSO, researchers have invested lots of efforts into its distribution characteristics and formation mechanism studies, while there are still many scientific issues remain to be resolved [19]. For instance, how to determine exactly the threshold of the BL thickness? What are the features of the BL and its ocean-atmosphere feedback characteristics during ENSO evolution? How to reproduce exact BL and its relevant thermodynamic processes in ENSO simulation? Besides, most of the BL studies of nowadays are still qualitative analysis, quantitative diagnosis is truly in-need for deepening of our understanding of BL in the tropical Pacific ocean.

\section{Acknowledgement}

Great thanks given to editor and reviewers for their valuable suggestions. This study is supported by Basic Scientific Research Funding of TIOMNR (2016025), "Thermohaline Structure of the western Pacific Warm Pool and its Climatic Effects" (DY135-E2-3-03) and "Physical Marine Environment and Typical Seamount Flow Field Structure in the western Pacific Seamount Regimes" (DY135-E2-2-02).

\section{References}

1. Lindstrom E, Lukas R, Fine R (1987) The western equatorial Pacific Ocean circulation study. Nature 330: 533-537.

2. Ando K, Mcphaden MJ (1997) Variability of surface layer hydrography in the tropical Pacific Ocean. Journal of Geophysical Research Oceans 102(C10): 23063-23078.

3. Godfrey JS, Lindstrom EJ (1989) The heat budget of the equatorial western Pacific surface mixed layer. Journal of Geophysical Research Oceans 94(C6): 8007-8017.

4. Lewis MR, Carr ME, Feldman GC, Wayne E, Chuck M (1990) Influence of penetrating solar radiation on the heat budget of the equatorial Pacific Ocean. Nature 347: 543-545.

5. Vialard J, Delecluse P (1998) An OGCM Study for the TOGA Decade. Part I: Role of salinity in the physics of the western pacific fresh pool. Journal of Physical Oceanography 28(6): 1071-1088.

6. Smyth WD, Hebert D, Moum JN (1996) Local ocean response to a multiphase westerly wind burst. Part 2: Thermal and freshwater responses. J Geophys Res 101(C10): 22513-22533. 
7. Jiang LH, Chen D (2012) Temporal and spatial characteristics of the barrier layer thickness in the tropical Pacific Ocean. Oceanographic Research 30(2): 14-20.

8. Vialard J, Delecluse P (1998) An OGCM Study for the TOGA Decade. Part II: Barrier-Layer Formation and Variability. Journal of Physical Oceanography 28(6): 1089-1106.

9. Maes C, Picaut J, Belamari S (2005) Importance of the salinity barrier layer for the buildup of el niño. Journal of Climate 18(1): 104-118.

10. Sprintall J, Tomczak M (1992) Evidence of the barrier layer in the surface layer of the tropics. Journal of Geophysical Research Oceans 97(C5): 7305-7316.

11. Montégut CDB (2004) Mixed layer depth over the global ocean: An examination of profile data and a profile-based climatology. Journal of Geophysical Research Oceans 109(C12).

12. Chen D (2004) Upper ocean response to surface momentum and freshwater fluxes in the western Pacific warm pool. Journal of Tropical Oceanography 23: 1-15.

13. Bosc C, Delcroix T, Maes C (2009) Barrier layer variability in the western Pacific warm pool from 2000 to 2007. Journal of Geophysical Research Oceans 114(C6): 06023.
14. Cronin MF, Mcphaden MJ (2002) Barrier layer formation during westerly wind bursts. Journal of Geophysical Research Oceans 107(C12).

15. Maes C, Picaut J, Belamari S (2002) Salinity barrier layer and onset of El Niño in a Pacific coupled model. Geophysical Research Letters 29(24): 59.

16. Liu HL, Grodsky SA, Carton JA (2009) Observed sub seasonal variability of oceanic barrier and compensated layers. Journal of Climate 22(22): 6104-6119.

17. Wang X, Liu H (2016) Seasonal-to-interannual variability of the barrier layer in the western Pacific warm pool associated with ENSO. Climate Dynamics 47(1-2): 1-18.

18. Mcphaden MJ, Zebiak SE, Glantz MH (2006) ENSO as an integrating concept in earth science. Science 314(5806): 1740-1745.

19. Smyth WD, Hebert D, Moum JN (1996) Local ocean response to a multiphase westerly wind burst: 2 . Thermal and freshwater responses. Journal of Geophysical Research Oceans 101(C10): 22513-22533.

For possible submissions Click below: 